\title{
Parental Leave and the Glass Ceiling in Sweden*
}

\author{
James Albrecht \\ Department of Economics, Georgetown University \\ albrecht@georgetown.edu \\ Peter Skogman Thoursie \\ Department of Economics, Stockholm University \\ Peter.thoursie@ne.su.se \\ Susan Vroman \\ Department of Economics, Georgetown University \\ vromans@georgetown.edu
}

September 2014

\begin{abstract}
In this paper, we update and extend "Is There a Glass Ceiling in Sweden?" (Albrecht, Björklund and Vroman, JOLE 2003) by documenting the extent to which the gender log wage gap across the distribution in Sweden has changed over the period 1998 - 2008. We then examine the Swedish glass ceiling in 2008 in more detail by documenting how it differs for white-collar versus blue-collar workers and for private- versus public-sector workers. We also examine when in the life cycle the glass ceiling effect arises and how this effect develops around the birth of the first child. Finally, we investigate the possible connection between the glass ceiling and the parental leave system in Sweden by linking wage data with data on parental leave from different Swedish registers.

JEL Classification: J16, J31, J71

Keywords: gender gap, parental leave, quantile regression

* This research was supported by a grant from IFAU, Uppsala. A presentation based on this material was given as the Presidential Address by the first author at the European Society of Population Economics in Braga, Portugal in June 2014.
\end{abstract}




\section{Introduction}

Ten years ago, Albrecht, Björklund and Vroman (2003) documented the existence of a substantial glass ceiling in Sweden, i.e., a large difference between the wages earned by men and women at the top of their respective distributions. Using register data from 1998, they found that although the difference between the median log wage for males and the median log wage for females was 0.133 (quite low by international standards), the corresponding gap at the $90^{\text {th }}$ percentile was 0.387 (extremely high by developed country standards). Several later studies, e.g., Arulampalam, Booth and Bryan (2007), examined the gender log wage gap across the distribution in other European countries. With the exception of the other Scandinavian countries, there is less of a glass ceiling elsewhere in Europe; indeed, in some southern European countries, the gender log wage gap declines across the distribution.

Albrecht et al. (2003) hypothesized that the generous parental leave system was a major factor contributing to the glass ceiling in Sweden. Their argument was based on statistical discrimination. Before we discuss that argument, we note that there are, of course, several other potential explanations for the Swedish glass ceiling. One possibility is that career interruptions, e.g., for parental leave, may be associated with lower levels of human capital. See, for example, Mincer and Ofek (1982) and Kim and Polachek (1994). This might occur in two ways. First, human capital may depreciate while one is away from work. We argue, however, that human capital depreciation is unlikely to be the primary explanation for the Swedish glass ceiling. Albrecht, Edin, Sundström and Vroman (1999) estimated the effects of time out of the workforce on log wages for men and women in Sweden while controlling for individual-specific fixed effects. They found that while women's wages were not affected by "normal" periods of parental leave, men who took parental leave suffered a substantial wage penalty. These findings seem incompatible with a pure human capital depreciation effect - if time out depreciates human capital and if this depreciation leads to wage losses, then the effects should be similar for men as for women. ${ }^{1}$ A second reason that parental leave might be associated with lower levels of human capital is that workers who anticipate career interruptions in the future have less incentive to

\footnotetext{
${ }^{1}$ This is not to suggest that there is no depreciation of human capital. See Edin and Gustavsson (2008) for some direct evidence based on the International Adult Literacy Survey. They show that survey respondents' ability to read and make use of practical information decreased with time out of work.
} 
invest in human capital today than do those who expect to work more or less continuously. However, pre-market levels of human capital investment, in particular, educational attainments, are similar for men and women in Sweden. Indeed, female educational attainment has surpassed that of males in Sweden (Pekkarinen 2012).

A second potential alternative explanation for the glass ceiling in Sweden is gender differences in career orientation; that is, women may self-select into more family-friendly jobs with corresponding flatter wage profiles as a matter of preference. Some papers, e.g., Croson and Gneezy (2009) and Bertrand (2011) argue that women are less competitive, more risk averse, less over-confident and less likely to initiate negotiations. However, this issue is by no means settled; for example, studies of bankers show that women are less risk averse, and other studies suggest that women in competitive settings are at least as aggressive as males. Again, see Croson and Gneezy (2009) and Bertrand (2011). In any event, the question is why the glass ceiling effect is so pronounced in Sweden and the other Scandinavian countries relative to what we see elsewhere. Any argument based on gender differences in career orientation needs to explain why such differences are particularly salient in the Scandinavian countries.

Finally, a third alternative explanation is that there is a limited market for household services in economies such as Sweden that have a compressed wage structure and that women in top jobs may need these services to succeed in the labor market. The argument is that in countries like the U.S., career-oriented women can hire someone to clean the house, pick up the children after school, etc. at a relatively low wage, while in Sweden, such "outsourcing" is much more expensive. This explanation has been advanced by Arulampalam, Booth and Bryan (2007), among others, and, even though public daycare (dagis) is available at a relatively early age in Sweden, ${ }^{2}$ we think it has considerable merit. Interestingly, the market for household services has grown substantially in recent years in Sweden, spurred in part by a relatively generous tax-rebate program known as RUT. ${ }^{3}$ Some early results on the labor market effects of RUT are given in Halldén and Stenberg (2013).

\footnotetext{
${ }^{2}$ Municipalities have the obligation to provide dagis starting at age one, but in some municipalities there are queues so it sometimes takes somewhat longer to get a place in day care.

3 Since July 1, 2007, a 50\% deduction can be taken for the cost of outsourced housework such as Rengöring (Cleaning), Underhåll (Maintenance) and Tvätt (Washing). Since July 1, 2009, this deduction has been taken directly; that is, the buyer pays $50 \%$ of the amount stated on the invoice with the service provider requesting
} 
Having sketched these alternatives, our primary explanation for the glass ceiling in Sweden remains one of statistical discrimination. The argument is essentially that of Coate and Loury (1993). ${ }^{4}$ Employers understand that the Swedish parental leave system gives women a strong incentive to participate in the labor force but also encourages them to take long periods of parental leave and to be less flexible with respect to hours once they return to work. Extended absence and lack of flexibility are particularly costly for employers when employees hold top jobs. ${ }^{5}$ Employers therefore place relatively few women in fast-track career positions. Women, even those who would otherwise be strongly career-oriented, understand that their promotion possibilities are limited by employer beliefs and respond rationally by opting for more familyfriendly career paths and by fully utilizing their parental leave benefits. The equilibrium is thus one of self-confirming beliefs. Women may "choose" family-friendly jobs, but choice reflects both preferences and constraints. Our argument is that what is different about Sweden (and the other Scandinavian countries) is the constraints that women face and that these constraints - in the form of employer expectations - are driven in part by the generosity of the parental leave system.

In this paper, we update and extend Albrecht et al. (2003) by documenting the extent to which the gender log wage gap across the distribution in Sweden has changed over the period 1998 - 2008. We then examine the Swedish glass ceiling in 2008 in more detail by documenting how it differs for white-collar versus blue-collar workers and for private- versus public-sector workers. We also examine when in the life cycle the glass ceiling effect arises and how this effect develops around the birth of the first child. Finally, we investigate the possible connection between the glass ceiling and the parental leave system in Sweden. To do this, we link wage data with data on parental leave from different Swedish registers. We focus on young men and women who had their first child in the period 1994 - 98 and then follow the career paths of these individuals. We estimate quantile regressions relating log wages in 2008 to patterns of parental leave utilization.

\footnotetext{
the remainder directly from the Swedish Tax Authority. One motivation for this program was to discourage the black market in household services. In addition to RUT, there is another program known as ROT whereby a 50\% tax deduction can also be taken for craft services in the home such as Reparation (Repair), Ombyggnad (Refurbishment) and Tillbyggnad (Extension). ROT preceded RUT, albeit at a lower rate of deduction. Currently, the maximum deduction for RUT and ROT together is 50,000 SEK (about \$7600) per person. ${ }^{4}$ Coate and Loury (1993) develop their model to help explain racial wage differences. See Albanesi and Olivetti (2009) for an application of the Coate and Loury (1993) model to gender wage differences.

${ }^{5}$ Specifically, using U.S. data, Goldin (2014) argues that absence and lack of commitment are particularly costly in jobs that require long and/or flexible hours.
} 
In particular, we look at how much parental leave the individuals take for their first child and whether the parental leave is concentrated or spread out.

We find that the gender log wage gap toward the top of the distribution decreased from 1998 to 2008 but that there is still a significant glass ceiling in 2008 and it is still considerably larger than in other developed countries. This reduction in the glass ceiling occurred against a backdrop of increasing overall wage inequality over the 1990's, but during the early 2000's, wage differentials changed little. ${ }^{6}$

When we examine the gender log wage gap by occupation, we find that the glass ceiling is a phenomenon only for the wage distributions of white-collar workers and not for blue-collar workers. Focusing on white-collar workers, we find that the glass ceiling effect is present in both the private and public sectors and is particularly strong in the public sector at the provincial government level. The glass ceiling effect increases with age (up to age 45), and over half of the difference in log wages between men and women is present even before the birth of the first child. After the first birth, the gap increases, especially at the very top. Finally, there is a wage gap between mothers who concentrate their parental leave and those who don't, even before the birth of the first child.

We then use quantile regressions to control for education, age, family size, occupation, sector and parental leave utilization. We estimate these quantile regressions separately for women and men whose first child was born in the years 1994 - 98 and who held a white-collar job in 2008. We use two variables to capture parental leave utilization: the total parental leave taken and the share of parental leave taken in the first half year after the birth. Total parental leave taken has a negative coefficient that is significant throughout the distribution for fathers and is greater in absolute value than the corresponding coefficient estimates for mothers across all quantiles used. For mothers, total parental leave is negative and significant for the median and above. For both fathers and mothers, the coefficient is greater in absolute value for the higher quantiles. The fact that the coefficients are larger in absolute value for the fathers is consistent with the findings of Albrecht, Edin, Sundström, and Vroman (1999), who found that taking parental leave had a negative effect on fathers relative to other men whereas taking parental leave had little effect on

\footnotetext{
${ }^{6}$ See Bengtsson, Edin, and Holmlund (2014).
} 
mothers. For mothers, the share of parental leave taken in the first half year has a consistently positive and increasing coefficient that is significant at the $25^{\text {th }}$ percentile and above. In sum, we find that taking parental leave has a larger effect at the higher end of the wage distribution. The effect is larger for fathers, but fathers take less parental leave. Mothers who concentrate their leave suffer less wage loss, particularly at the high end of the distribution. The amount of parental leave taken by mothers and fathers and the way in which that leave is taken is closely associated with the glass ceiling.

We start in the next section by describing the data. Then, in Section 3, we briefly describe the Swedish parental leave system. In Section 4, we present a descriptive analysis of how the gender gap across the distribution changed in Sweden betweem 1998 and 2008. We then focus on the gender log wage gap in 2008 and look at how it differs by occupation, sector, and age. In Section 5 , we look at how the gender wage log gap changes around the birth of the first child and with parental leave utilization. Finally, in Section 6, we conclude.

\section{The Data}

We use Swedish population-wide register data for our analysis. Our starting point is the LOUISE database, which contains information from several registers for the Swedish population aged 16 75. This database includes annual labor earnings, age, education, country of origin, region of residence, etc. These data are available on an annual basis. We use data over the period 1994 2008.

We link several other registers to the basic LOUISE database. First, only data on annual earnings are available in LOUISE. Information on full-time-equivalent monthly earnings (thus comparable to hourly wage rates) is available in the Wage Structure Statistics and is based on (i) the individual's earnings during the survey month (often September) and (ii) his or her contracted hours for that month. These data are available only for individuals who had some working hours during the month of the survey; in particular, workers on leave (e.g., parental leave) for the entire month are not included. Full-time-equivalent earnings are available for all public-sector employees with positive hours in the survey month. In the private sector, these data are available for all workers in firms with at least 500 employees. For firms with fewer than 500 employees, a stratified sample (based on industry and on firm size) is used. As a result, approximately $50 \%$ of 
private-sector workers are included in our database. The analysis we present below uses weights to adjust for the fact that full-time-equivalent earnings are not observed for all private-sector workers.

We also link two other registers to LOUISE, the Multiple Generation Register and the Parental Leave Register. The Multiple Generation Register records all births, which makes it possible to keep track of the number and age of children associated with each mother and father. LOUISE includes a family identifier, so that the database can be used to trace spouses, but the Multiple Generation Register gives additional information since a biological mother and father can be divorced. The Parental Leave Register gives start and end dates for periods when benefits have been paid.

\section{The Swedish Parental Leave System}

The current Swedish parental leave system is summarized in the diagram below. The system is very generous by international standards. Parents are allowed a total of 480 days that can be taken any time up until the child turns 8 years old. Of the 480 days, 390 days are paid at close to 80 percent of the individual's salary up to a cap. ${ }^{7}$ In 2013, the maximum daily allowance was SEK 946 or about $\$ 135$. The remaining 90 days are paid at a flat rate. Nonworking parents also can receive a parental allowance at this flat rate. Of the 390 days, 60 days are reserved for each parent. That is, if one parent does not take two months of leave, the other parent cannot take an

\footnotetext{
${ }^{7}$ Some employers top up the benefit to $90 \%$ of the wage for a number of months, but we do not have data on this.
} 


\section{The current Swedish tax-paid parental leave system}

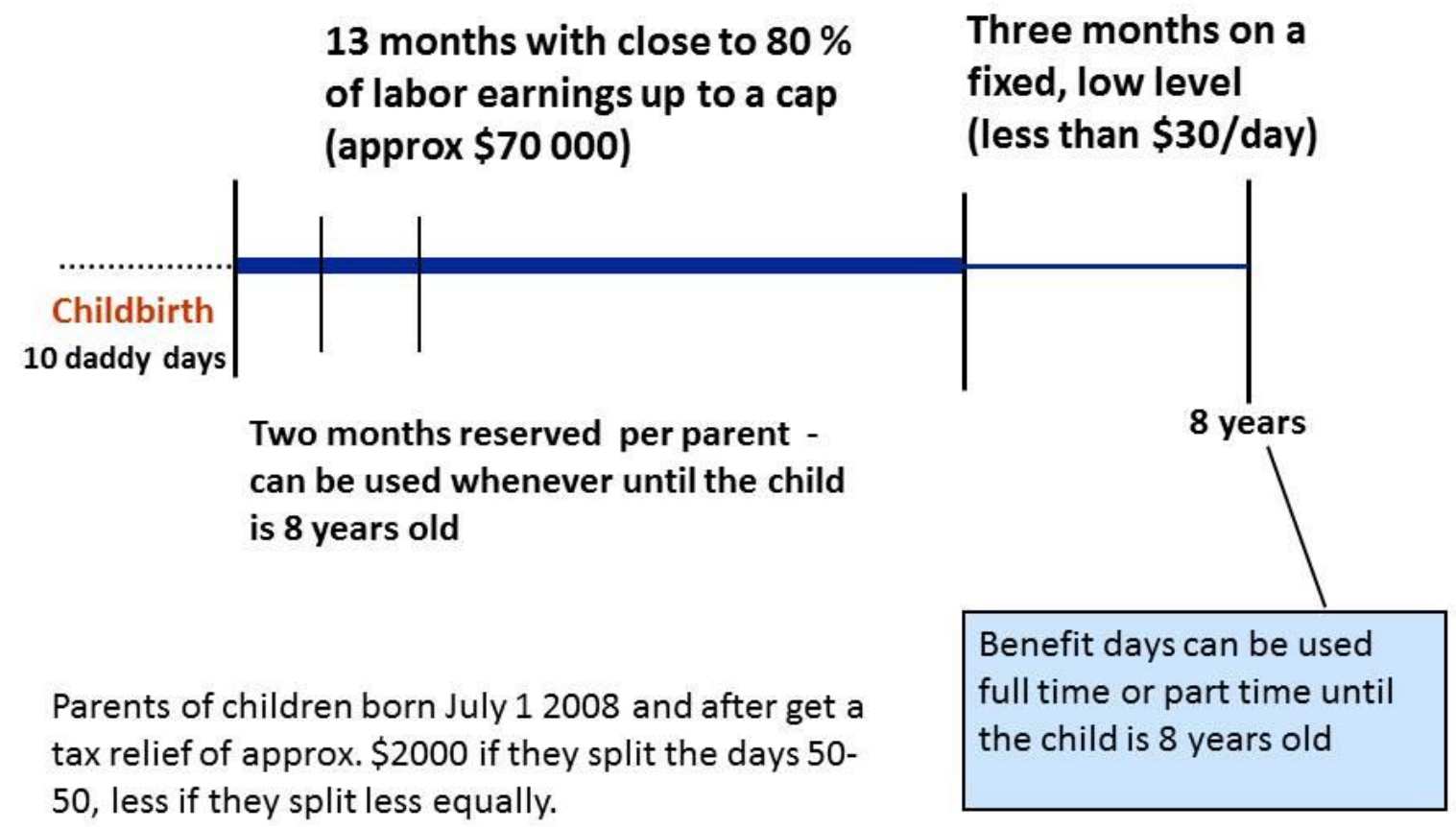

Note: We thank Anna Thoursie for providing this figure.

extra two months; i.e., there are 60 days for each parent and then 270 days that can be allocated in any manner the parents choose. ${ }^{8}$ If the 270 days are shared evenly by the parents, they get a tax-free bonus of SEK50 per day. Single parents have access to the full 480 days. ${ }^{9}$ As illustrated in Figure $\mathrm{A}$ in the Appendix, the share of parental leave taken by fathers has increased steadily over time (note the spikes at the start of 1995 and 2002). In the period 1994 to 1998, fathers took about $10 \%$ of parental leave; currently, they take over $30 \%$ of parental leave. As noted in the diagram, parents can use the parental leave part time - indeed, the 480 days can be taken as full, half, quarter or even one eighths of a day - and can thus spread out their leave over a longer

8 The first "daddy month" - so-called because the objective was to give fathers more incentive to share in parental leave - was introduced in January, 1995; and the second daddy month was introduced in January, 2002. See Ekberg, Eriksson and Friebel (2013) for a regression discontinuity analysis of some of the effects associated with the introduction of the first of these reforms.

${ }^{9}$ Most of this information can be found on the website sweden.se/society/gender-equality-in-sweden/ 
period. In addition, by law, an individual has the right to work at 75 percent of full time until the child turns eight.

\section{Basic Descriptive Analysis}

\section{a. The Change in the Gender Log Wage Gap: 1998 - 2008}

Figure 1 presents the gender log wage gap across the wage distribution for Sweden in 1998 and 2008. The graph includes data for all men and women aged 25 to 60 for whom we have full-time equivalent earnings in September of the survey year. The data are weighted to account for sample stratification by industry affiliation and firm size class. It is apparent that the gender log wage gap is smaller at all quantiles in 2008 than it was in 1998, but the gender log wage gap decreased the most above the $75^{\text {th }}$ percentile of the distributions. That is, there has been a decline in the glass ceiling. Nonetheless, the gender log wage gap above the $75^{\text {th }}$ percentile is still quite substantial in 2008 rising to more than $0.3 \log$ points so that we conclude that there is still a significant glass ceiling in 2008 .

Figure 1. Gender log wage gaps across the distribution for men and women aged 25-60; 1998 and 2008

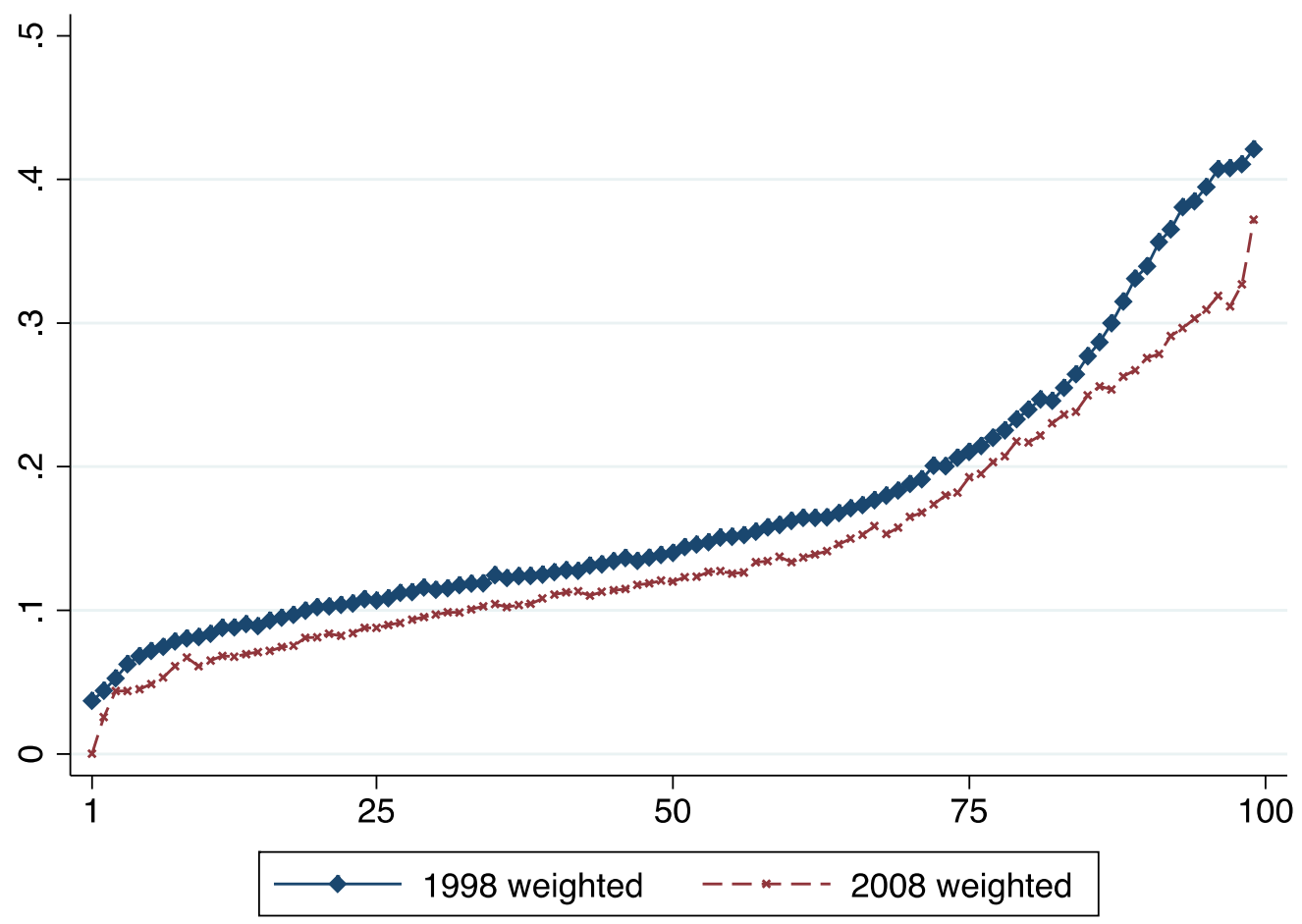




\section{b. The Gender Log Wage Gap: Sector and Occupation}

To get a better sense of which women are affected by the glass ceiling in 2008, we look at gender log wage gaps across the distribution by sector and occupation. Again, this is shown for men and women aged $25-60$ using weighted data. Overall in 2008, women made up 53.6 percent of white-collar workers and 44.1 percent of blue-collar workers. In the public sector, women were 69.8 percent of white-collar workers, while they were 43.1 percent of white-collar workers in the private sector. ${ }^{10}$ Figure 2 shows the gender log wage gaps for public-sector and private-sector white-collar and blue-collar workers. The gender log wage gaps are more or less constant over the wage distribution for blue-collar workers in both sectors. The gender log wage gap for bluecollar workers in the public sector is close to zero up to the median and a bit higher thereafter but doesn't show the large acceleration seen for the white-collar workers towards the top of the wage distribution. Based on Figure 2, one can see that the glass ceiling (the strong increase in the gender log wage gap across the distribution) is a characteristic of the wage distribution for whitecollar workers but not of that for blue-collar workers. Further, white-collar wages are in general higher than blue-collar wages. Specifically, in the blue-collar distribution, the log wages (monthly full-time equivalent earnings) at the $90^{\text {th }}$ percentile (10.13 for women and 10.28 for men) are below the $90^{\text {th }}$ percentile of the overall log wage distribution (10.43 for women and 10.70 for men) while the log wages at the $90^{\text {th }}$ percentile of the white-collar distribution (10.53 for women and 10.88 for men) are above the $90^{\text {th }}$ percentile of the overall distribution. That is, the difference in the higher quantiles between the overall distributions for men and women is primarily driven by the difference in the white-collar distributions, and this difference exhibits the glass ceiling pattern. In this sense, the glass ceiling is a white-collar phenomenon. In the rest of this section, we restrict our attention to white-collar workers.

The gender log wage gap for private-sector white-collar workers rises over the wage distribution and grows particularly sharply at the very top of the distribution. For public-sector white-collar

\footnotetext{
10 The gender composition in the public and private sectors and between white collar and blue collar occupations has changed over time. In 2008, women made up a larger share of white-collar workers and a smaller share of blue-collar workers in both the public and private sectors than they had in 1998. See Table A1 in the Appendix for details.
} 
workers, the gender log wage gap also rises across the distribution, but the gap falls at the very top of the distribution. This is explained in part by disaggregating the public sector data. Figure 3 plots the gender log wage gap for public-sector white-collar workers by level of government. This shows that the gender log wage gap is highest in the Landsting or provincial government and climbs to extremely high levels (between 0.6 and $0.7 \log$ points) around the $75^{\text {th }}$ percentile before falling off. Even after falling off, the gender log wage gap for provincial government workers remains above $0.3 \mathrm{log}$ points. The gender log wage gap for white-collar workers in provincial government reflects to a large extent occupational segregation in the healthcare sector, which is administered at the provincial government level. Of the women in provincial government whose full-time equivalent monthly earnings were above the $75^{\text {th }}$ percentile in 2008 , the most frequent occupations were doctors $(30.2 \%)$, nurses $(8.7 \%)$, and department heads in the healthcare sector (5.7\%). For men, these were: doctors $(87.9 \%)$, department heads not in the healthcare sector $(5.0 \%)$, and holders of high office making political decisions $(1.4 \%)$.

Figure 2. Gender log wage gaps across the distribution for men and women aged 25-60 in 2008 by sector and occupation

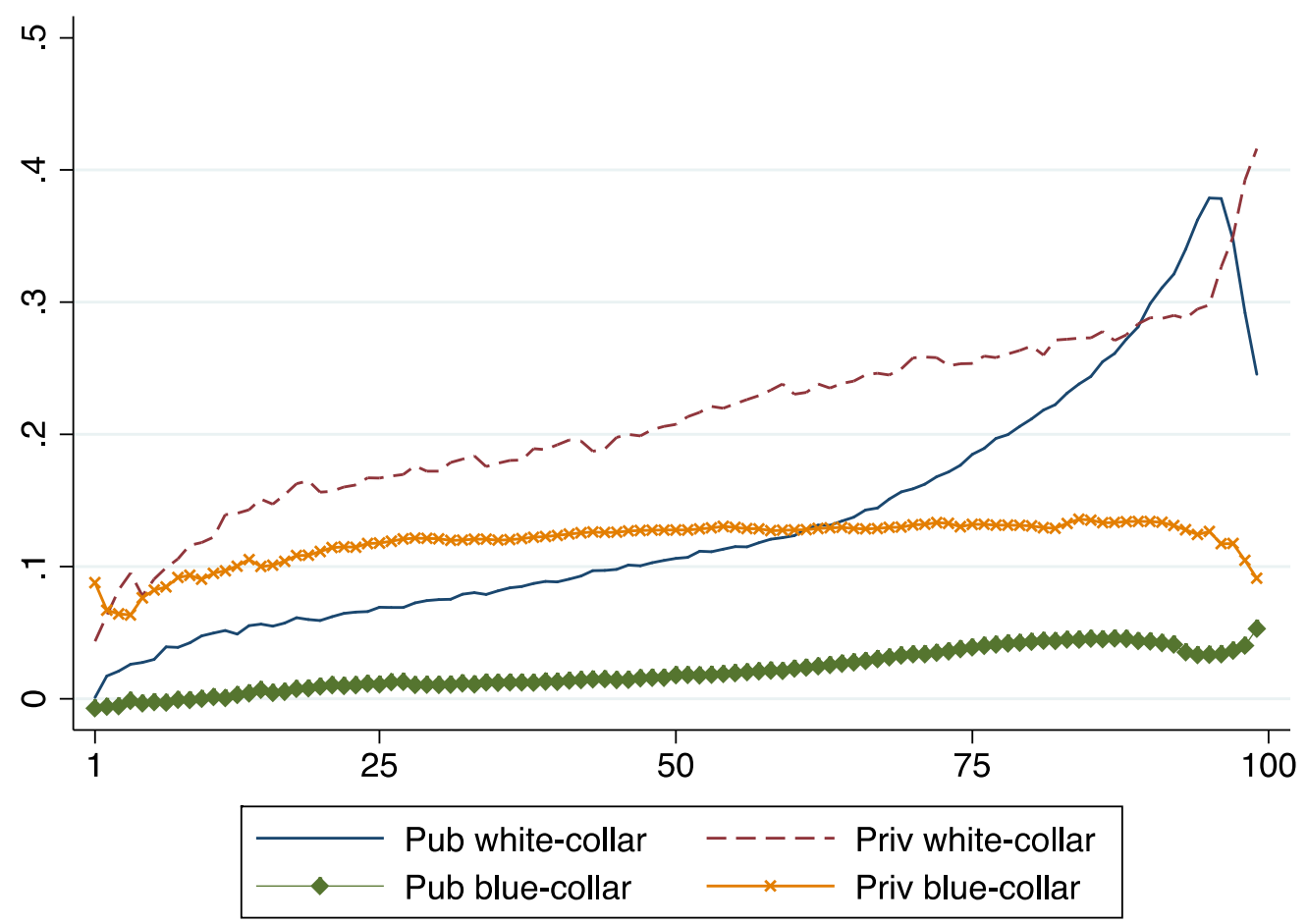


Figure 3. Gender log wage gaps across the distribution for white-collar public sector workers aged $25-60$ in 2008

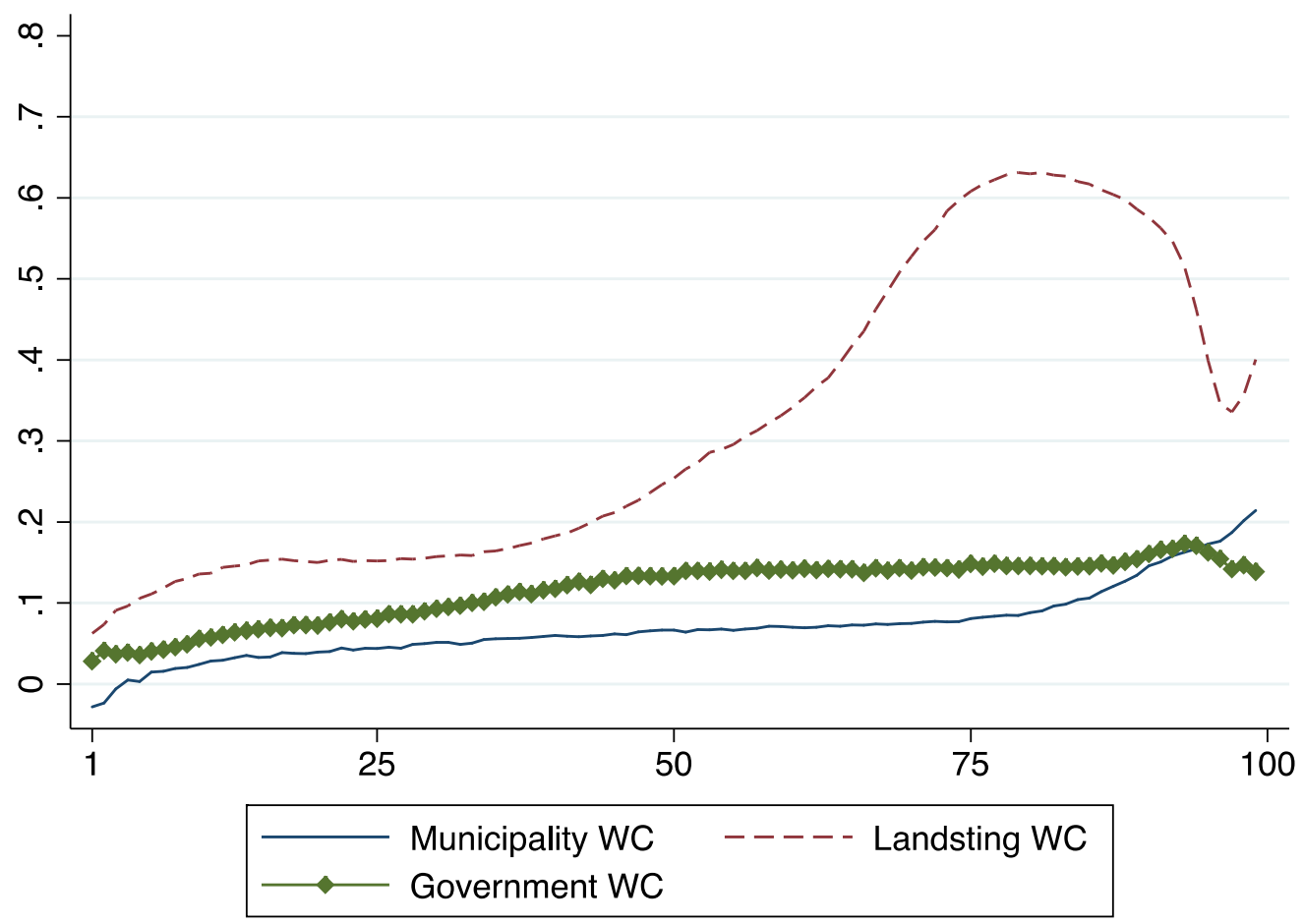

The next two figures illustrate the development of the gender log wage gap for white-collar workers over the period 1998 to 2008. Figure 4 looks at private-sector workers and shows that the gender log wage gap at the $90^{\text {th }}$ percentile fell over this period and approached that at the $75^{\text {th }}$ percentile, which had also decreased over the period. The gaps at the $10^{\text {th }}, 25^{\text {th }}$, and $50^{\text {th }}$ percentiles were essentially constant over this period. Figure 5 shows a quite different picture for the white-collar workers in the public sector. The gender log wage gap at the $90^{\text {th }}$ percentile increased a bit over the period and remained significantly above the gaps at the lower percentiles, which were essentially constant over the entire period. 
Figure 4. Annual development of Gender Log Wage Gaps. Private white-collar workers

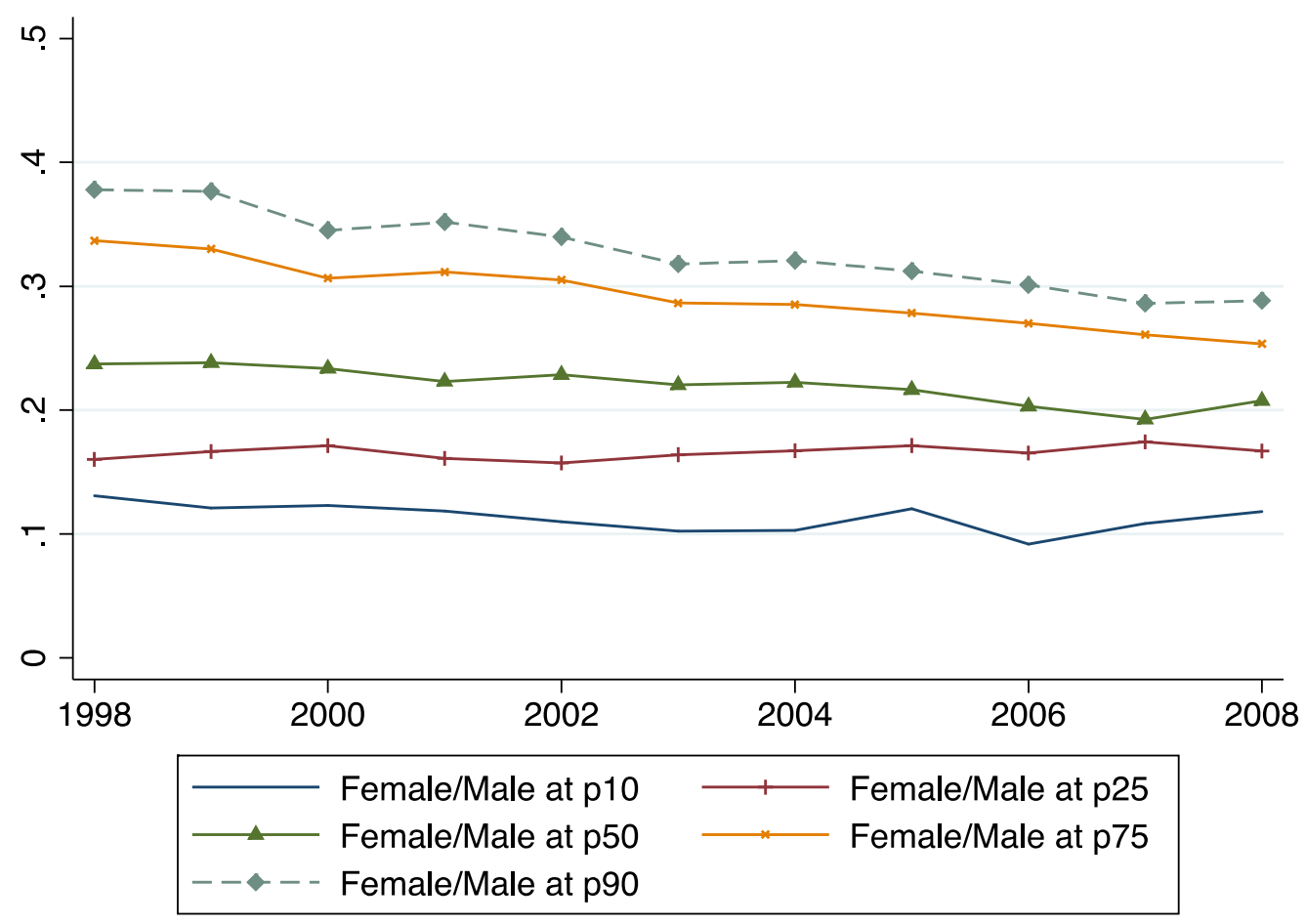

Figure 5. Annual development of Gender Log Wage Gaps. Public white-collar workers

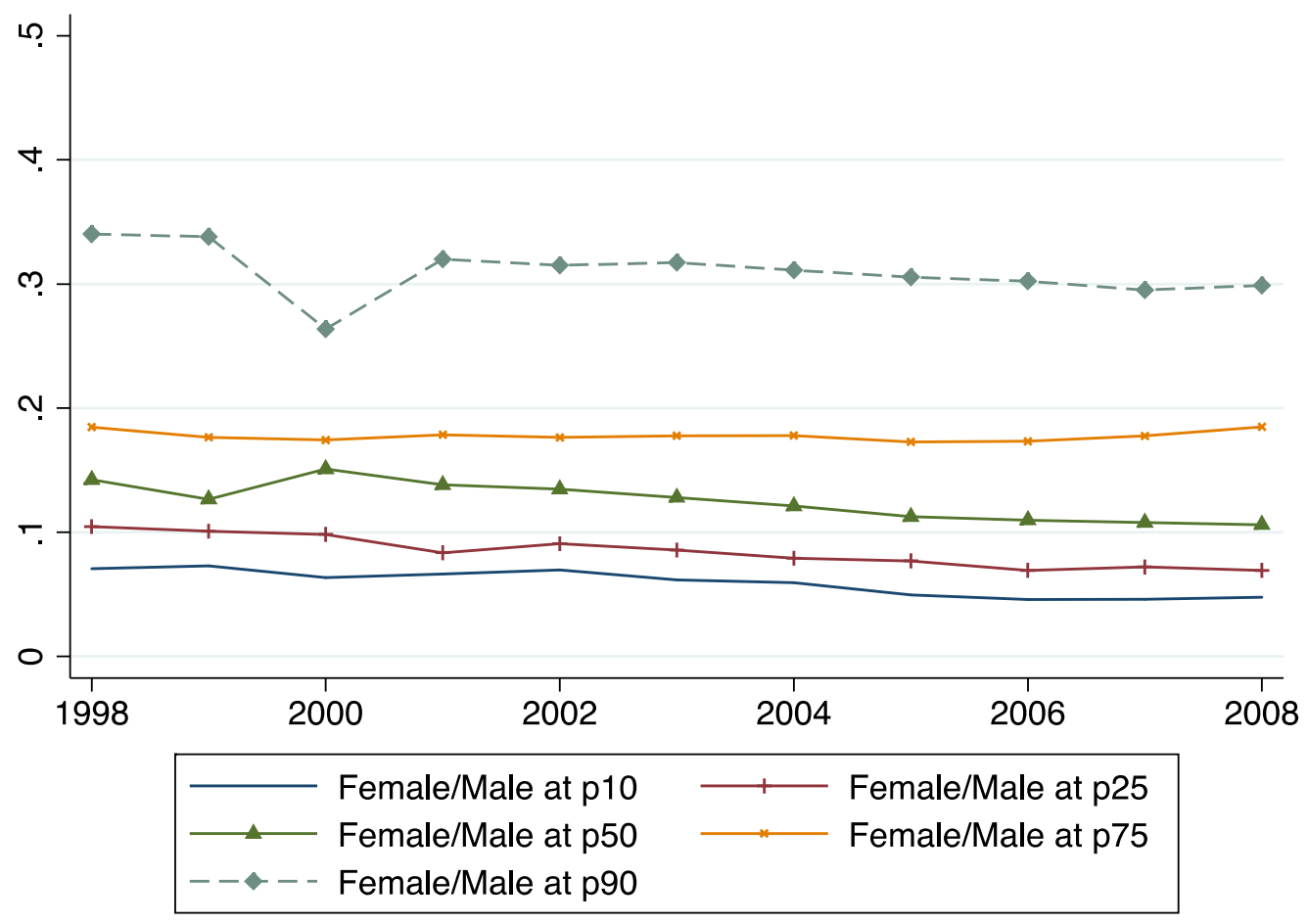


Figures 6 and 7 show the development of the gender log wage gap for white-collar workers at the median and the $90^{\text {th }}$ percentile over $1998-2008$ by age groups. In Figure 6, we see that the gender log wage gap at the median increases up to age 35 and remains relatively constant over this time period for each age group. In fact, the biggest increase is between ages 25 and 35 when the gap rises from less than 10 percent to almost 20 percent. This is in line with the results found in Angelov et al. (2013), which shows that the spousal wage and income gaps increase by 10 and 35 percent respectively, fifteen years after the birth of the first child. Figure 7 shows much larger increases in the log wage gap at the $90^{\text {th }}$ percentile. Here we see that the gap continues to rise until age 45 and reaches very high levels - about twice as high as the levels shown for the median in Figure 6.

Figure 6. Annual development of gender wage gaps at the 50th percentile across age groups. White collar workers

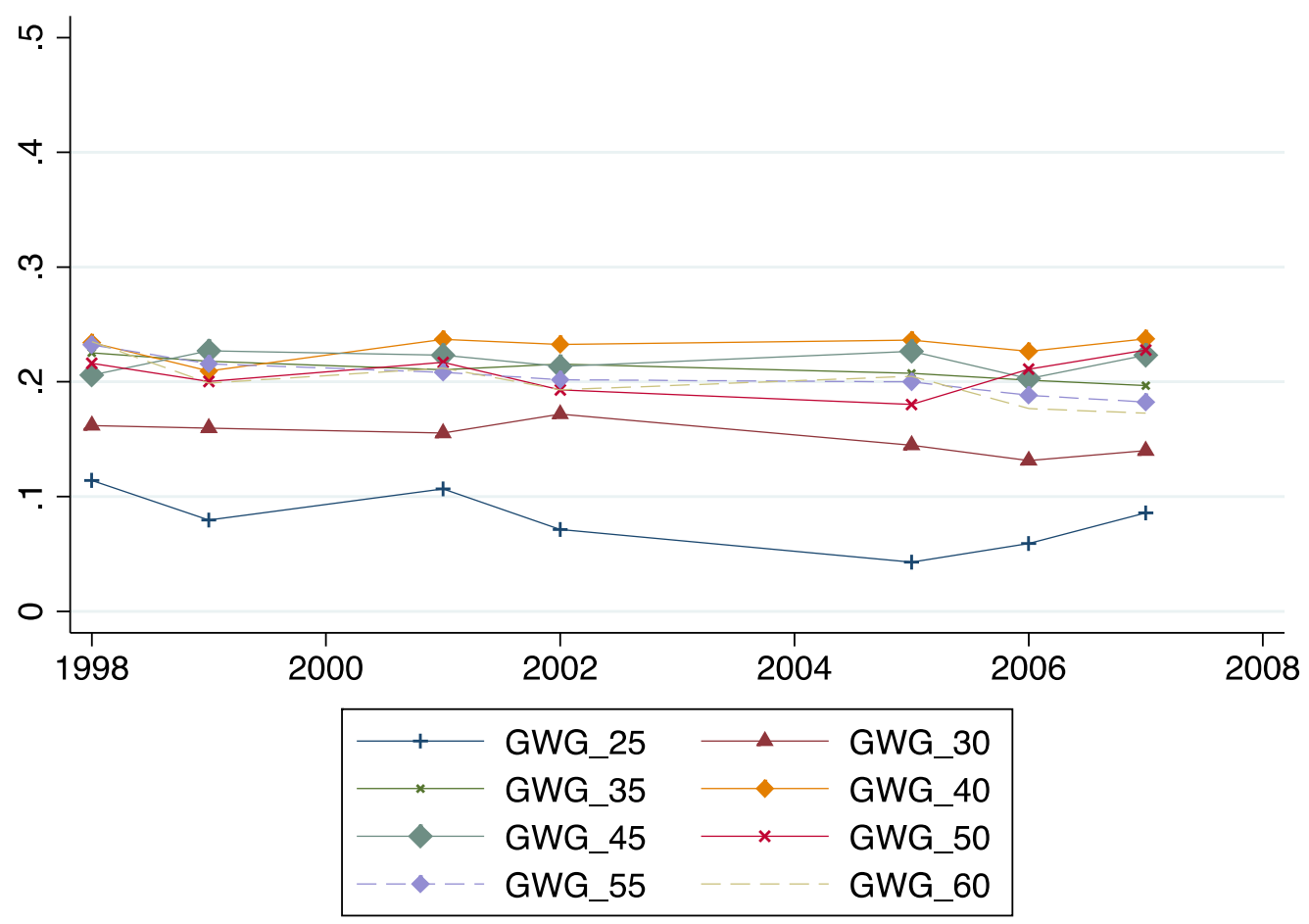


Figure 7. Annual development of gender wage gaps at the $90^{\text {th }}$ percentile across age groups. White collar workers

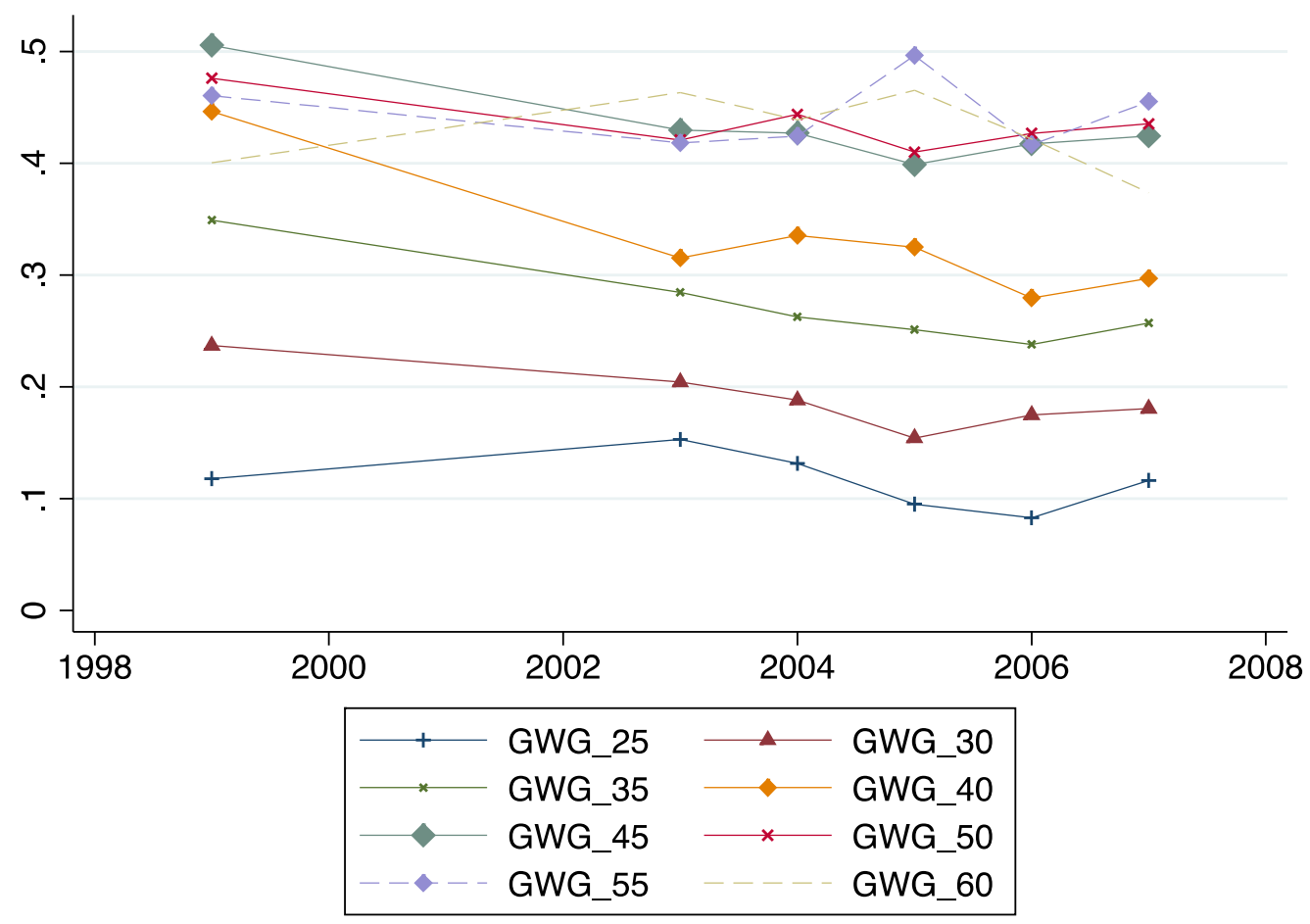

\section{Parental Leave and the Gender Log Wage Gap in 2008}

\section{a. The Gender Gap Before and After the First Birth}

In this section, we focus on men and women whose first child was born during the years $1994-$ 98 and who held white-collar jobs in 2008. We look at the gender log wage gap before and after the first birth, and then examine how that gap varies with how much parental leave is taken and whether it is taken in a concentrated or spread-out way. Figure 8 shows the gender log wage gap across the distribution for white-collar workers 4 years before the first birth, 1 year before the birth, 5 years after the first birth and 10 years after the birth. At the $25^{\text {th }}$ percentile, there is roughly a $10 \%$ log wage gap four years before the first birth. This gap doubles by ten years after the birth. At the median, the log wage gap four years before the first birth triples by ten years after the birth. Finally, at the $75^{\text {th }}$ percentile, the log wage gap ten years after the first birth is about four times the gap that existed four years before the birth. These patterns are consistent with the ones shown in Figures 6 and 7. In the lower half of the wage distribution, most of the 
gender gap is realized by age 35; in the upper half of the distribution, the spreading out continues through age 45. That is, part of what we see in Figure 8 may be a birth effect, but part may be a pure age effect. These patterns are also illustrated in Figure 9, which shows more clearly how the gender log wage gap increases continuously after the first birth for workers at the median, the $75^{\text {th }}$ percentile and the $90^{\text {th }}$ percentile of the log wage distribution.

Figure 8. Gender Wage Gaps by percentile before and after first birth. White collar workers

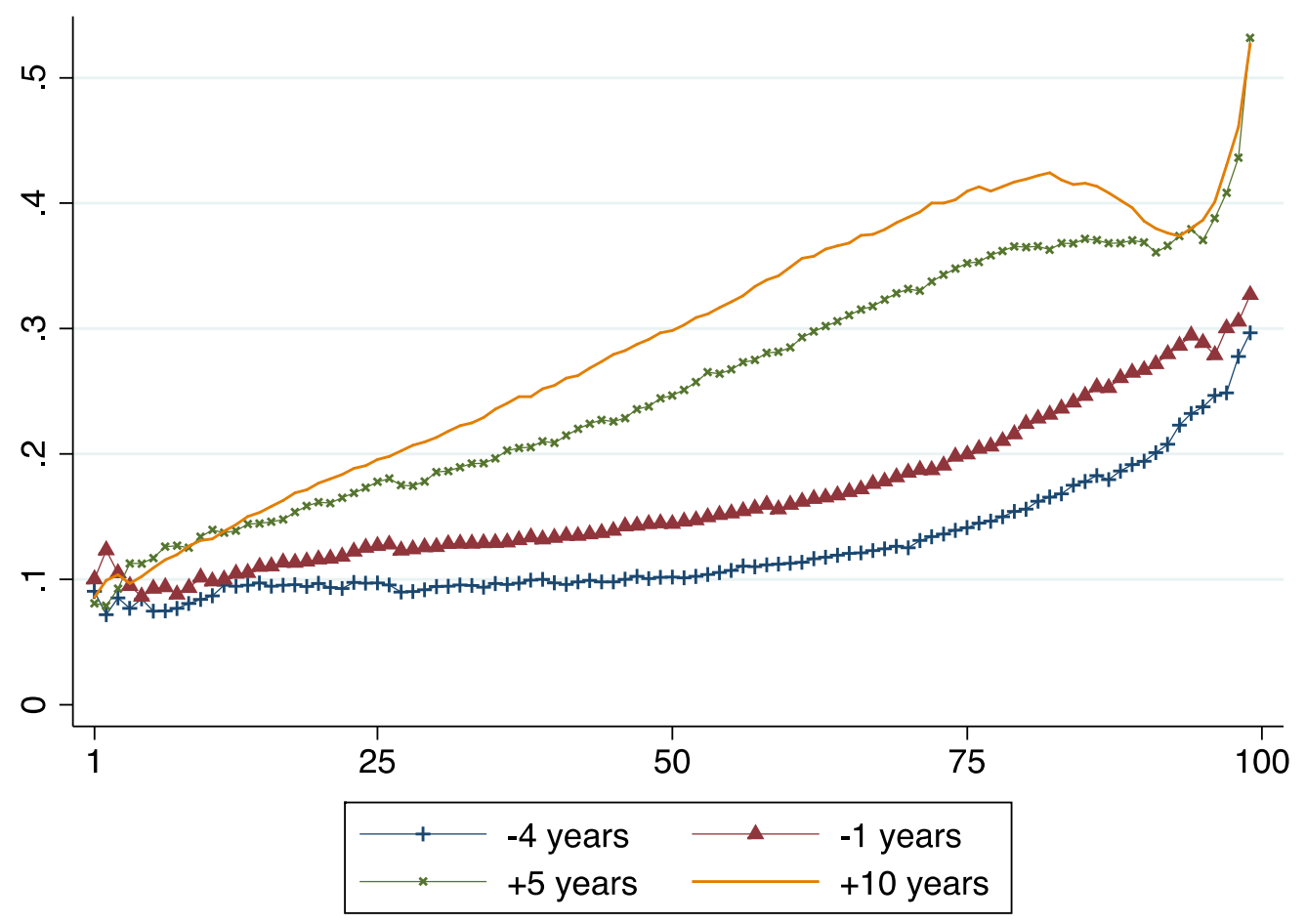


Figure 9. Development of Gender Wage Gaps years before and after first birth at different percentiles. White collar workers

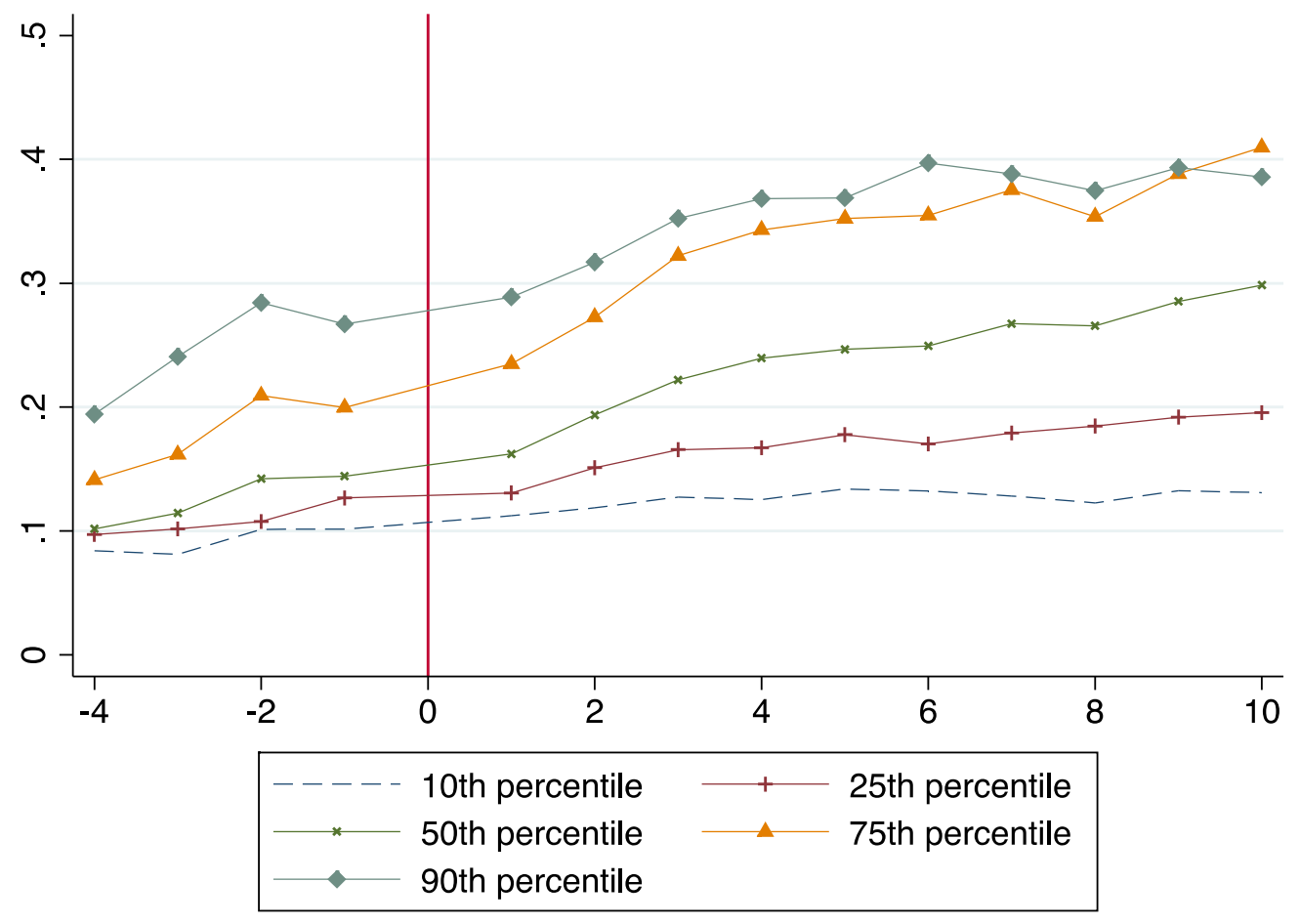

\section{b. The Effect of Parental Leave}

To examine how the gender log wage gap varies with parental leave, we estimate a set of quantile regressions for women and men separately so that we can look at the coefficients on parental leave variables while controlling for other factors. We are using $10 \%$ subsamples of men and women whose first child was born during the years 1994 - 98 and who hold white-collar jobs in 2008. Specifically, we use a subsample of 7,195 mothers and 4,941 fathers. These regressions include total parental leave taken (in months) in conjunction with the first birth, the share of parental leave that the parent took in the first half year after the first birth, family size, age, age squared, a dummy variable indicating whether the individual was employed in the private sector and a set of 2-digit occupational dummies, education dummies, and year dummies. Summary statistics for this subsample are given in Table A2 in the Appendix. We do not control for 
endogeneity of parental leave take-up, although this is clearly an issue, ${ }^{11}$ so the quantile regression estimates should be viewed as more of an accounting exercise than an indication of causality. The results are presented in Tables A3 and A4 in the Appendix.

The coefficient on total parental leave taken is negative and significant for mothers at the median and above. For fathers, total parental leave is negative and significant at the $25^{\text {th }}$ percentile and above. The coefficients for both mothers and fathers are larger in absolute value as we move up the distribution. Finally, the coefficients for fathers are larger in absolute value than those for mothers. These results are consistent with the findings in Albrecht et al. (1999), who found that parental leave take-up had a greater effect on the mean log wage of fathers than on the mean log wage of mothers. The share of parental leave taken in the first half year is significant for mothers from the $25^{\text {th }}$ percentile up. Its coefficient is positive and increases across the distribution. It is not significant for fathers. Our interpretation of the result for women is that women who concentrate their leave right after the child's birth rather than spreading it out are signaling more career commitment, and this has a larger effect on wages higher up in the wage distribution. Of course, it may be the case that women higher up the wage distribution are encouraged to concentrate their parental leave, i.e., this could be a reflection of the endogeneity of the timing of parental leave. The coefficient on the share of parental leave taken in the first six months after birth is insignificant at all quantiles for fathers. This is as expected since few fathers take substantial parental leave in the first half year.

Age is significantly positive for both women and men, but the coefficients for men are higher at every percentile. Being in the private sector has a positive effect on wages for both women and men, but again the coefficients are larger for men at every percentile. Interestingly, the occupation dummies are mostly significant for men but mostly insignificant for women. Finally, family size is not significant for women, but it is positive and significant for men from the $25^{\text {th }}$ percentile of the distribution.

11 The endogeneity issue is as follows. Some individuals may be more career-oriented than others, either inherently or as a result of their work and/or child-rearing experience. To the extent that career orientation is (i) negatively associated with the amount of parental leave taken and (ii) positively associated with subsequent wages, there will be a spurious negative association between parental leave take-up and subsequent wages. 
Figure 10a illustrates the coefficients on the first parental leave variable shown in Table A3, i.e., the total parental leave of mothers who had their first child between 1994 and 1998. It is clear from Figure 10a that, as indicated by the quantile regressions, the coefficient is significant and increasingly negative at the median and above. Figure $10 \mathrm{~b}$ illustrates the positive and increasing coefficient associated with concentrating one's parental leave right after having the child. Figures 10c and d show the analogous coefficients on the parental leave variables in the log wage equations for fathers. Figure 10c indicates that the coefficient on the total parental leave taken by fathers is negative and becomes more negative as we move up the wage distribution. The share taken in the first half year is never significant for fathers.

Figure 10a. The coefficient on months of parental leave in the log wage equations: Mothers

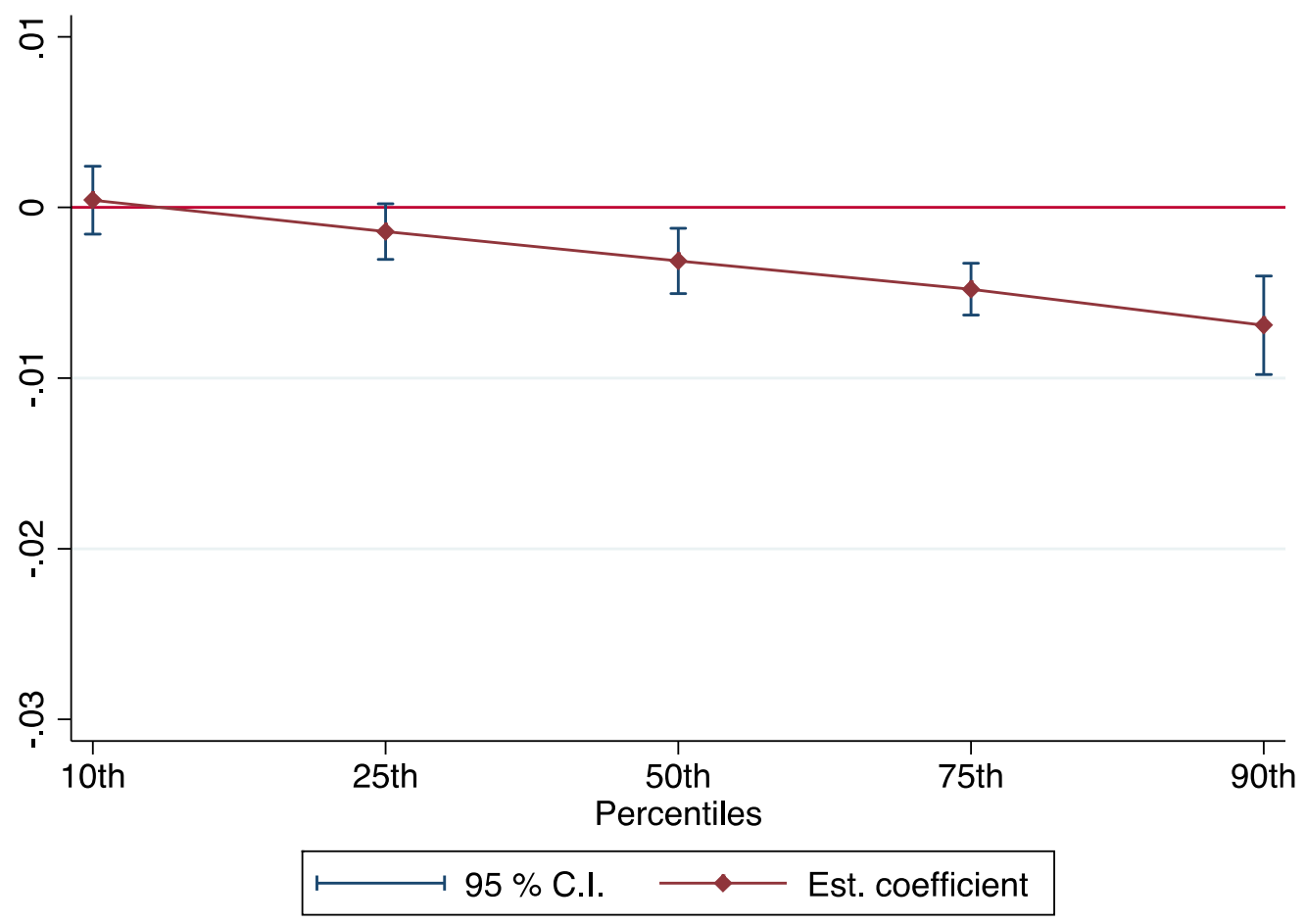


Figure 10b. The coefficient on fraction of leave in the first six months: Mothers

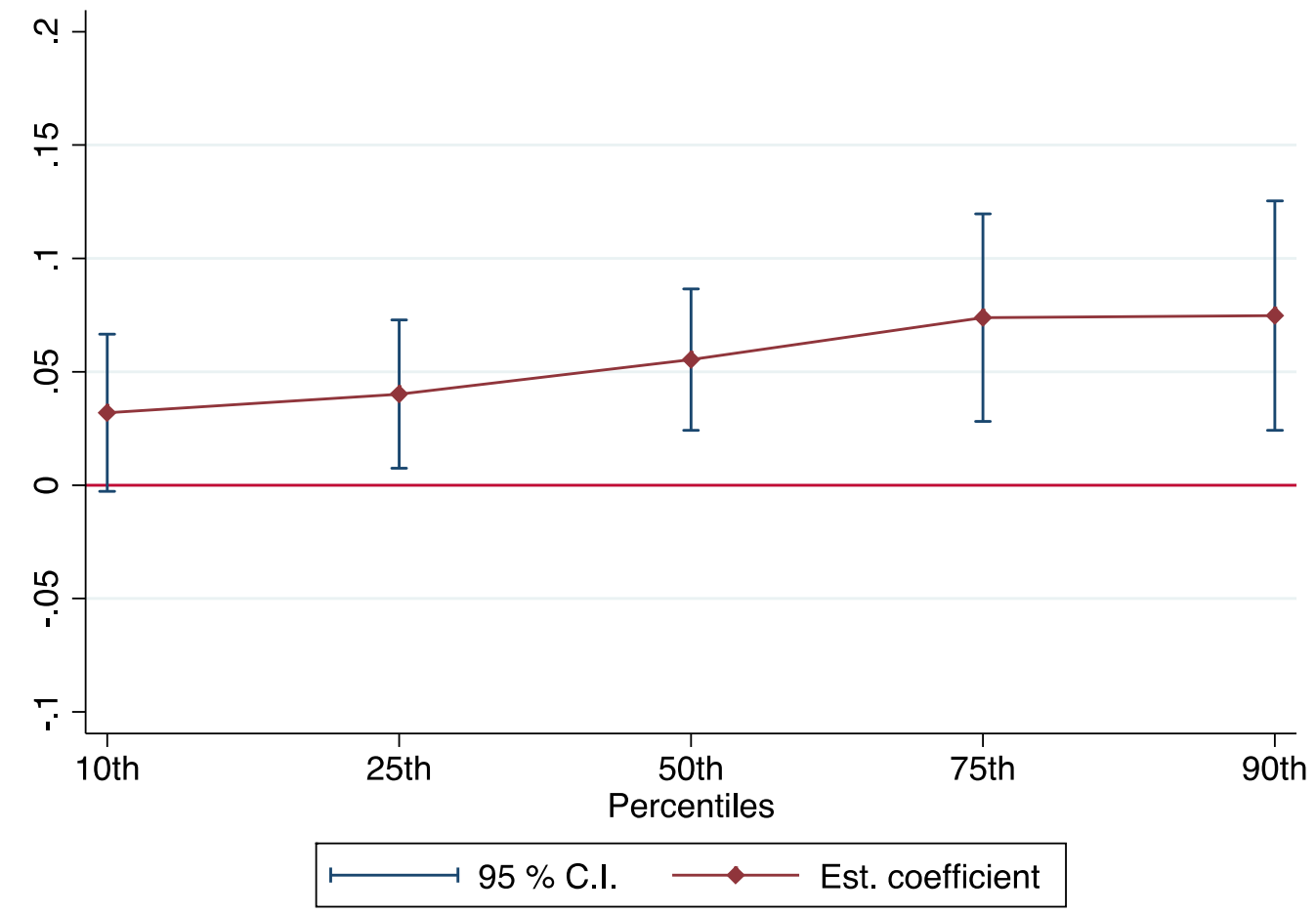

Figure 10c. The coefficient on months of parental leave in the log wage equations: Fathers

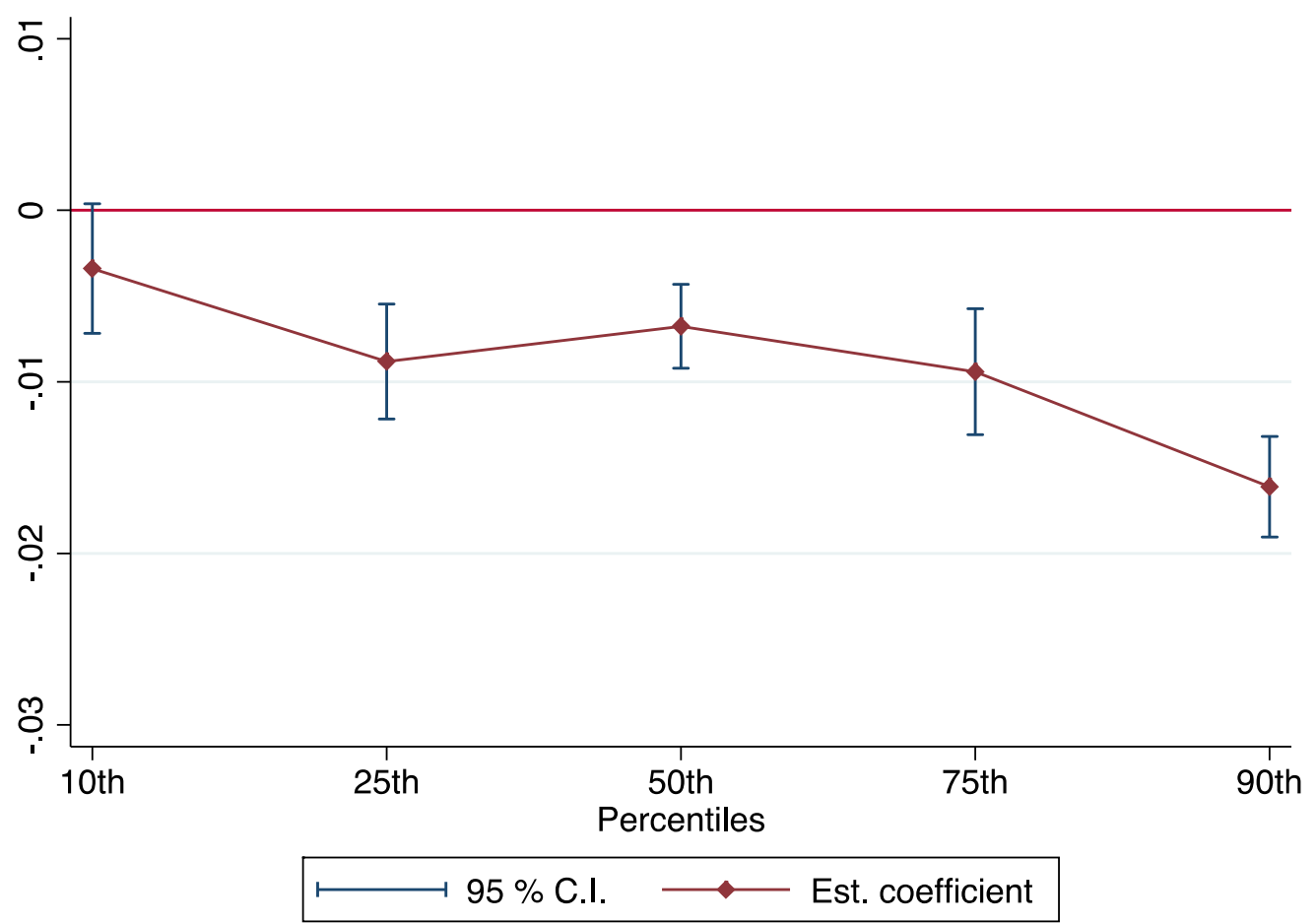


Figure 10d. The coefficient on fraction of leave in the first six months: Fathers

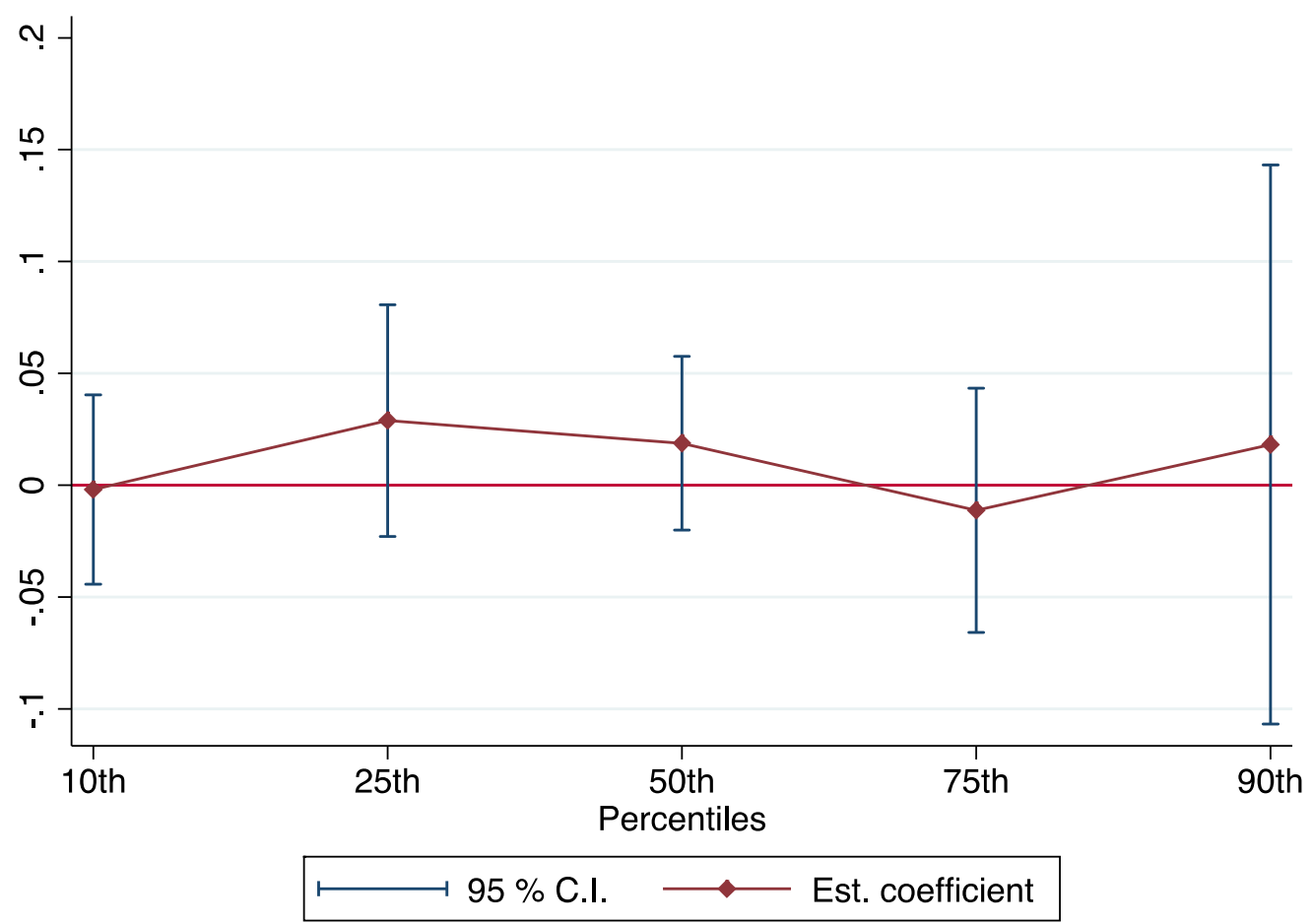

Finally, in Figures 11 and 12 we look more closely at the difference between women who concentrate their parental leave and those who don't. We define "concentrate parental leave" as taking half or more of the mother's days associated with the first child in the first six months after the birth. In Figure 11, we show the log wage gaps between mothers who concentrate their leave and those who don't. We show the gaps 4 years before the birth, one year before the birth, five years after the birth and 10 years after the birth. There is little gap for women in the bottom half of the wage distribution. Starting at the $75^{\text {th }}$ percentile of the wage distribution, we can see a significant difference between the women who concentrate their parental leave and those who don't. Those who concentrate their leave earn considerably more and the difference increases over time, i.e., the difference is greater 10 years after the birth than 5 years after the birth. This is consistent with the idea that concentrating one's parental leave signals more career commitment on the part of mothers so that they are in more "fast track" jobs and that this effect is apparent towards the top of the wage distribution. This is also illustrated in Figure 12, which shows that there is an increasing log wage gap at the $90^{\text {th }}$ percentile between the distribution across women who concentrate their leave and the distribution among those who don't concentrate their leave and are at the $90^{\text {th }}$ percentile of their wage distribution. 
Figure 11. Wage gaps between mothers who concentrate PL and those who don't by percentile before and after first birth. White collar workers

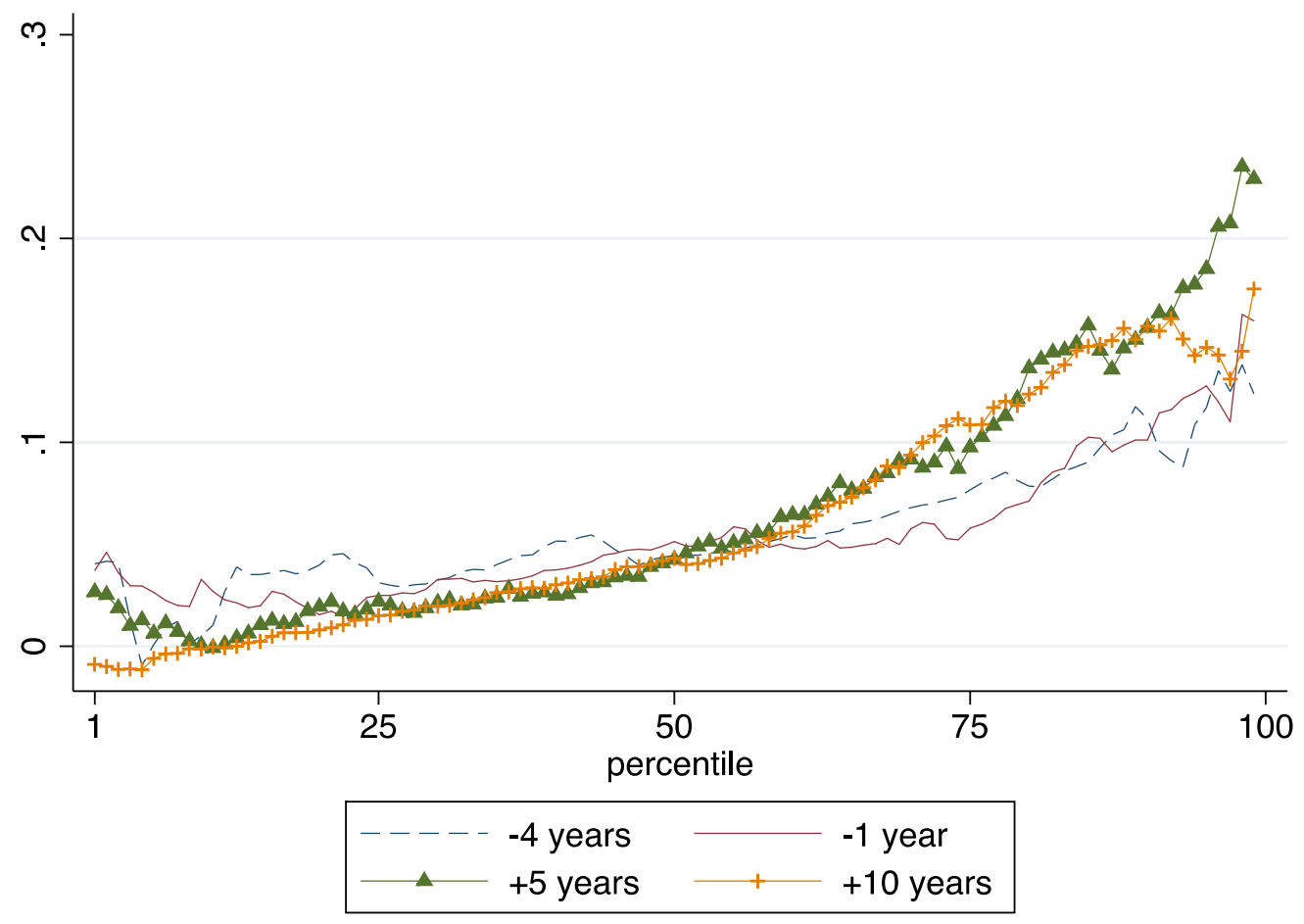

Figure 12. Development of wage gaps between mothers who concentrate PL and those who don't: years before and after first birth at various percentiles. White collar workers

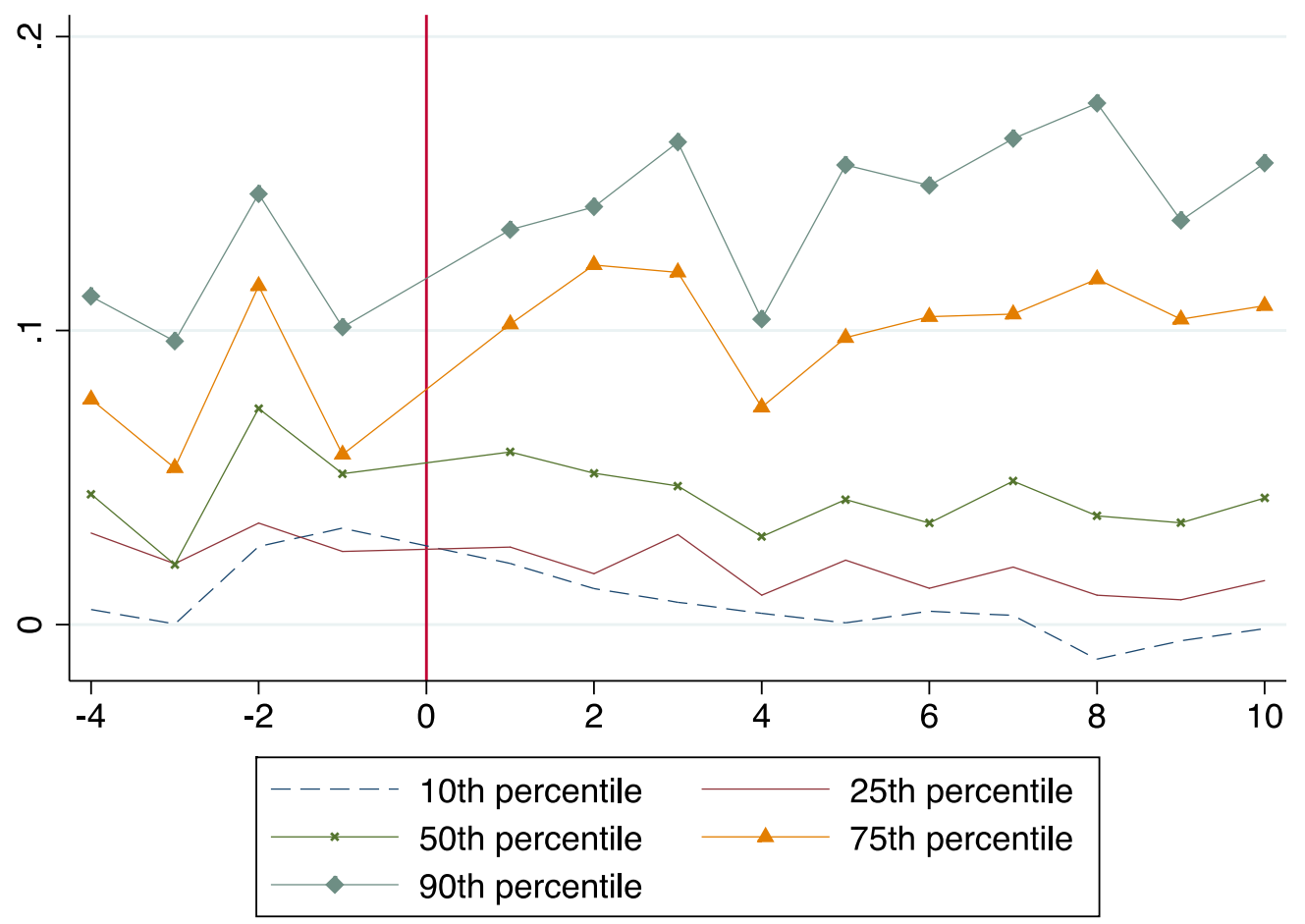




\section{Conclusion}

We have examined the gender log wage gap in Sweden. Using data from 1998 and 2008, we showed that the glass ceiling, i.e., a large and increasing gender log wage gap at the top of the wage distribution, has persisted over time. We looked at the data for 2008 and found that the glass ceiling is a white-collar phenomenon. There is a glass ceiling for white-collar workers in both the private and the public sectors, although the patterns are different. In the public sector, the gender log wage gap is quite different for different levels of government, being particularly large in the provincial government. We also found that the glass ceiling effect increases with age.

We then looked at how the gender log wage gap develops around the birth of the first child. Over half of the male-female log wage differential is present even before the first child is born. After the first birth, the gender log wage gap increases, especially at the $90^{\text {th }}$ percentile. We then looked at the relationship between parental leave and log wages. We ran quantile regressions for women and men who had their first child between 1994 and 1998 and who were working in white-collar jobs in 2008. We regressed log wages on months of parental leave, the fraction of parental leave taken in the first six months after the birth and a number of controls. We found that the coefficients on total parental leave were significantly negative for mothers from the median up and that they increased in absolute value as log wages increase. We found significant and increasingly negative coefficients for the fathers that were larger in absolute value than those for the mothers. We found significant positive coefficients for the log wages of mothers who concentrated their leave in the first six months that increased across the wage distribution. Concentrating leave had no significant effect on the log wages of fathers. These results are consistent with a signaling story in which mothers signal their commitment to their careers by concentrating their leave and this is more important the higher up the wage distribution they are. The larger effect of total parental leave taken for fathers also would support a signaling story in which these fathers signal a commitment to family by taking more than the normal paternal leave. Since almost all mothers take a substantial amount of maternal leave, total time taken does not provide a signal. 


\section{References}

Albanesi, Stephania and Claudia Olivetti (2009), "Home Production, Market Production and the Gender Wage Gap: Incentives and Expectations," Review of Economic Dynamics, 12, 80-107.

Albrecht, James, Björklund, Anders, and Susan Vroman (2003), "Is There a Glass Ceiling In Sweden?” Journal of Labor Economics, 21(1), 145-77.

Albrecht, James, Edin, Per-Anders, Sundström, Marianne, and Susan Vroman (1999), "Career Interruptions and Subsequent Wages: A Reexamination Using Swedish Data," Journal of Human Resources, 34(2), 294-311.

Angelov, Nikolay, Johansson, Per, and Erica Lindahl (2013), "Is the Persistent Gender Gap in Income and Wages Due to Unequal Family Responsibilities?" IFAU Working Paper 2013:3.

Arulampalam, Wiji, Booth, Alison, and Mark Bryan (2007), "Is There a Glass Ceiling over Europe? Exploring the Gender Pay Gap across the Wage Distribution," Industrial and Labor Relations Review, 60(2), 163-86.

Bengtsson, Niklas, Edin, Per-Anders, and Bertil Holmlund (2014), “Löner, sysselsättning och inkomster - ökar klyftorna i Sverige?” Rapport till Finanspolitiska rådet 2014/1,

Bertrand, Marianne (2011), "New Perspectives on Gender", Handbook of Labor Economics, Volume 4b, Elsevier Ltd., 1545-1592.

Coate, Stephen and Glenn Loury (1993), "Will Affirmative Action Policies Eliminate Negative Stereotypes?” American Economic Review, 83(5), 1220-40.

Croson, Rachel and Uri Gneezy (2009), “Gender Differences in Preferences,” Journal of Economic Literature, 47(2), 448-74.

Edin, Per-Anders and Magnus Gustavsson (2008), "Time Out of Work and Skill Depreciation," Industrial and Labor Relations Review, 61(2), 163-80.

Ekberg, John, Eriksson, Rikard and Guido Friebel (2013), "Parental Leave - A Policy Evaluation of the Swedish 'Daddy-Month' Reform," Journal of Public Economics, 97, 131-43.

Goldin. Claudia (2014), "A Grand Gender Convergence: Its Last Chapter," American Economic Review, 104(4), 1091-1119.

Halldén, Karin and Anders Stenberg (2013), "The Relationship Between Hours of Domestic Services and Female Earnings: Panel Register Data Evidence from a Reform," Working Paper 2013-10-07, Swedish Institute for Social Research (SOFI), Stockholm University.

Kim, Moon-Kak and Solomon Polachek (1994), "Panel Estimates of Male-Female Earnings Functions," Journal of Human Resources, 29(2), 406-428.

Mincer, Jacob and Haim Ofek (1982), "Interrupted Work Careers: Depreciation and Restoration of Human Capital," Journal of Human Resources, 17(1), 3-24. 
Pekkarinen, Toumas (2012), "Gender differences in education," Nordic Economic Policy Review, $1,165-195$.

\section{Appendix}

Figure A. The male share of PL use, 1989-2013

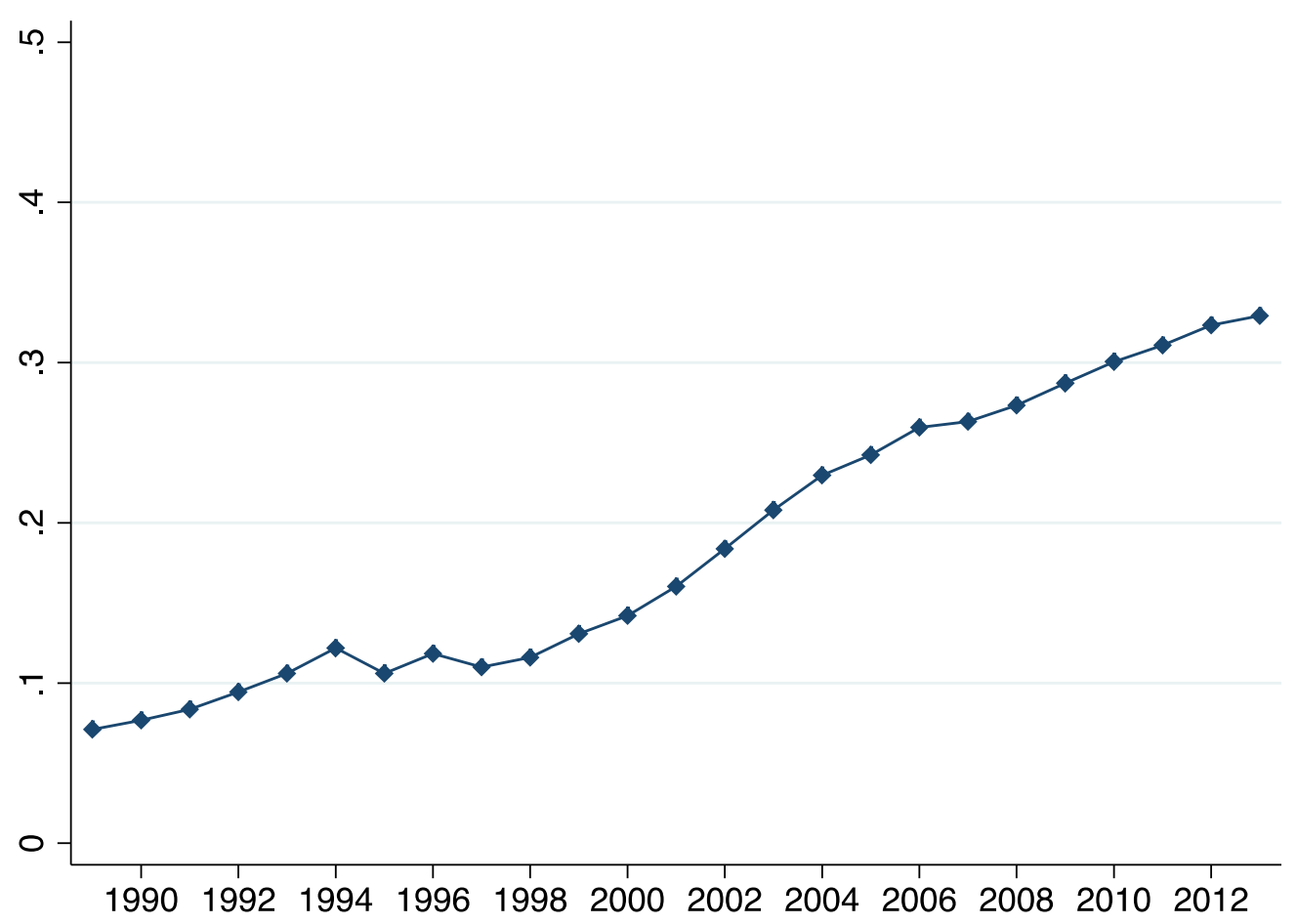

Source: National Social Insurance Board 


\begin{tabular}{|l|c|c|}
\hline \multicolumn{2}{|l|}{ Table A1: Share of Workers Aged $25-60$ by Sector and Occupation } \\
\hline & Female & Male \\
\hline 1998 & & 0.151 \\
\hline Public White Collar & 0.310 & 0.398 \\
\hline Private White Collar & 0.297 & 0.039 \\
\hline Public Blue Collar & 0.228 & 0.411 \\
\hline Private Blue Collar & 0.165 & \\
\hline & & \\
\hline 2008 & & 0.126 \\
\hline Public White Collar & 0.300 & 0.425 \\
\hline Private White Collar & 0.333 & 0.039 \\
\hline Public Blue Collar & 0.199 & 0.410 \\
\hline Private Blue Collar & 0.168 & \\
\hline
\end{tabular}


Table A2: Summary statistics by gender for mothers and fathers whose first child was born in 1994-98. White collar workers in 2008

\begin{tabular}{|l|l|l|}
\hline & Mothers & Fathers \\
\hline Total PL months & $\begin{array}{l}11.89 \\
(2.47)\end{array}$ & $\begin{array}{l}2.27 \\
(2.06)\end{array}$ \\
\hline $\begin{array}{l}\text { Share PL days taken within first half } \\
\text { year }\end{array}$ & $\begin{array}{l}0.370 \\
(0.148)\end{array}$ & $\begin{array}{l}0.086 \\
(0.213)\end{array}$ \\
\hline Age & $\begin{array}{l}40.87 \\
(4.52)\end{array}$ & $\begin{array}{l}42.79 \\
(4.89)\end{array}$ \\
\hline Private sector (0,1) & $\begin{array}{l}0.388 \\
(0.487)\end{array}$ & $\begin{array}{l}0.662 \\
(0.473)\end{array}$ \\
\hline Family size & $\begin{array}{l}2.05 \\
(0.68)\end{array}$ & $\begin{array}{l}2.09 \\
(0.71)\end{array}$ \\
\hline & & \\
\hline Education level & & 0.001 \\
\hline Pre secondary school $(<9$ years) & 0.001 & 0.029 \\
\hline Pre secondary school (9,10 years) & 0.014 & 0.327 \\
\hline Secondary school & 0.270 & 0.147 \\
\hline Post secondary school $(<2$ years) & 0.061 & 0.450 \\
\hline Post secondary school ( $\geq 2$ years) & 0.635 & 0.045 \\
\hline Post graduate education & 0.018 & 0.0008 \\
\hline Unknown & 0.0002 & 49,012 \\
\hline Sample Size & 72,347 & \\
\hline
\end{tabular}


Table A3: Quantile Regressions: Mothers

\begin{tabular}{|l|l|l|l|l|l|l|}
\hline & $\begin{array}{l}10^{\text {th }} \\
\text { Percentile }\end{array}$ & $\begin{array}{l}2^{\text {th }} \\
\text { Percentile }\end{array}$ & $\begin{array}{l}50^{\text {th }} \\
\text { Percentile }\end{array}$ & $\begin{array}{l}75^{\text {th }} \\
\text { Percentile }\end{array}$ & $\begin{array}{l}90^{\text {th }} \\
\text { Percentile }\end{array}$ & OLS \\
\hline & & & & & & \\
\hline Total PL & 0.000 & -0.001 & -0.003 & -0.005 & -0.007 & -0.005 \\
& $(0.001)$ & $(0.001)$ & $(0.001)$ & $(0.001)$ & $(0.001)$ & $(0.001)$ \\
\hline Share 1st Half & 0.032 & 0.040 & 0.055 & 0.074 & 0.075 & 0.090 \\
Year & $(0.018)$ & $(0.017)$ & $(0.016)$ & $(0.023)$ & $(0.026)$ & $(0.019)$ \\
\hline Family Size & 0.003 & 0.001 & 0.000 & 0.003 & -0.002 & 0.004 \\
& $(0.004)$ & $(0.004)$ & $(0.004)$ & $(0.005)$ & $(0.007)$ & $(0.004)$ \\
\hline Age & 0.040 & 0.042 & 0.047 & 0.050 & 0.060 & 0.065 \\
& $(0.006)$ & $(0.005)$ & $(0.004)$ & $(0.005)$ & $(0.004)$ & $(0.006)$ \\
\hline Age ${ }^{2}$ & -0.000 & -0.000 & -0.000 & -0.000 & -0.001 & -0.001 \\
& $(0.000)$ & $(0.000)$ & $(0.000)$ & $(0.000)$ & $(0.000)$ & $(0.000)$ \\
\hline Private & 0.045 & 0.069 & 0.120 & 0.191 & 0.256 & 0.151 \\
& $(0.006)$ & $(0.004)$ & $(0.005)$ & $(0.010)$ & $(0.015)$ & $(0.006)$ \\
\hline Constant & 9.416 & 9.440 & 9.380 & 9.346 & 9.131 & 8.937 \\
& $(0.180)$ & $(0.127)$ & $(0.183)$ & $(0.164)$ & $(0.227)$ & $(0.136)$ \\
\hline Adjusted R ${ }^{2}$ & & & & & & \\
\hline Pseudo R ${ }^{2}$ & 0.2446 & 0.2672 & 0.3093 & 0.3794 & 0.4492 & \\
& & & & & & 0.5087 \\
\hline All estimations & & & & & & \\
\hline
\end{tabular}

All estimations include controls for seven education levels (see explanation in Table A2) and 26 occupation categories based on a two-digit classification. 
Table A4: Quantile Regressions: Fathers

\begin{tabular}{|l|l|l|l|l|l|l|}
\hline & $\begin{array}{l}1^{\text {th }} \\
\text { Percentile }\end{array}$ & $\begin{array}{l}5^{\text {th }} \\
\text { Percentile }\end{array}$ & $\begin{array}{l}50^{\text {th }} \\
\text { Percentile }\end{array}$ & $\begin{array}{l}75^{\text {th }} \\
\text { Percentile }\end{array}$ & $\begin{array}{l}90^{\text {th }} \\
\text { Percentile }\end{array}$ & OLS \\
\hline & & & & & & \\
\hline Total PL & -0.003 & -0.009 & -0.007 & -0.009 & -0.016 & -0.012 \\
& $(0.002)$ & $(0.002)$ & $(0.001)$ & $(0.002)$ & $(0.001)$ & $(0.002)$ \\
\hline Share 1st Half & -0.002 & 0.029 & 0.019 & -0.011 & 0.018 & 0.002 \\
Year & $(0.022)$ & $(0.026)$ & $(0.020)$ & $(0.028)$ & $(0.064)$ & $(0.019)$ \\
\hline Family Size & 0.008 & 0.017 & 0.031 & 0.032 & 0.034 & 0.028 \\
& $(0.008)$ & $(0.007)$ & $(0.007)$ & $(0.008)$ & $(0.013)$ & $(0.006)$ \\
\hline Age & 0.054 & 0.060 & 0.071 & 0.065 & 0.098 & 0.089 \\
& $(0.007)$ & $(0.011)$ & $(0.012)$ & $(0.012)$ & $(0.014)$ & $(0.010)$ \\
\hline Age ${ }^{2}$ & -0.001 & -0.001 & -0.001 & -0.001 & -0.001 & -0.001 \\
& $(0.000)$ & $(0.000)$ & $(0.000)$ & $(0.000)$ & $(0.000)$ & $(0.000)$ \\
\hline Private & 0.096 & 0.141 & 0.214 & 0.266 & 0.329 & 0.234 \\
& $(0.013)$ & $(0.007)$ & $(0.011)$ & $(0.014)$ & $(0.028)$ & $(0.010)$ \\
\hline Constant & 8.527 & 8.230 & 8.206 & 8.298 & 7.661 & 7.688 \\
& $(0.226)$ & $(0.323)$ & $(0.346)$ & $(0.243)$ & $(0.395)$ & $(0.243)$ \\
\hline & & & & & & \\
\hline Adjusted R & & & & & & 0.4268 \\
\hline Pseudo R ${ }^{2}$ & 0.2349 & 0.2546 & 0.2916 & 0.3100 & 0.3047 & \\
\hline
\end{tabular}

All estimations include controls for seven education levels (see explanation in Table A2) and 26 occupation categories based on a two-digit classification. 